IJMS 20 (2), (15-28) (2013)

\title{
PRIORITIZING OF CRITERIA IN TEACHER-CANDIDATE SELECTION PROCESS BY ANALYTIC HIERARCHY PROCESS
}

\author{
MAZNAH MAT KASIM \\ RAZAMIN RAMLI \\ HASLINDA IBRAHIM \\ MOHD IZAM GHAZALI \\ FAZILLAH MOHMAD KAMAL \\ S.VIKNESWARI \\ UUM College of Arts $\mathcal{E}$ Sciences \\ Universiti Utara Malaysia
}

\begin{abstract}
This paper reviews and identifies the criteria used in the teacher-candidate selection process. The identified main criteria and sub-criteria were prioritized according to their importance by a group of experts. The literature was the source of the criteria and twelve experts who have experience in teacherselection process were asked to justify the criteria obtained from the secondary source. Furthermore, these experts evaluated the relative importance of the identified criteria in a pair-wise manner. Their judgments were analysed by a multi-criteria method, known as the Analytic Hierarchy Process.
\end{abstract}

Three main criteria were identified which consisted of 'content of knowledge', 'communication skills' and 'personality', while each of these three main criteria had four, six and eight sub-criteria respectively. The degree of importance which is known as weights of these criteria were also calculated where those criteria which receive higher values are considered to be more important. Generally, the results of the analysis show that 'communication skills' and 'personality' are the most and second-most important criteria respectively, followed by 'content of knowledge' in the third position. The analysis of the importance of the sub-criteria of these three main criteria is also included.

These criteria and the weights can be used later in the development of the teacher-selection model. Both secondary data and primary data were used in this research. All the experts or the respondents have experience in the selection process where $40 \%$ of them have more than six years' experience. 
Keywords: Analytic Hierarchy Process (AHP), importance, multi-criteria, selection, teacher, weights.

\section{Introduction}

The demand for trained teachers in Malaysia is increasing every year due to the increase in the number of schools since its independence. A total of 7695 primary schools and 2248 secondary schools have been established in Malaysia, as of $30^{\text {th }}$ June 2010 (Ministry of Higher Education, 2010) to educate and shape the students. Following the increase in the number of schools, approximately 126171 male teachers and 279545 female teachers were working in primary and secondary schools as of $30^{\text {th }}$ June 2010 . Many local universities and teacher-training institutes are offering teacher-training programmes throughout Malaysia. There are 21 local universities and 31 teachertraining institutes which offering training programmes throughout Malaysia. These teaching institutes and universities are offering training programmes at diploma, undergraduate and postgraduate levels.

Besides meeting the increasing demand of teachers, the quality of the teachers should be given serious attention. 'Recruited widely' and 'selected carefully' should be the priority (United States of America Department of Education, 2008). Qualified and capable candidates should be selected who may contribute towards achieving the Education Philosophy of Malaysia (Sang, 2005). Therefore, a selection process is done with the aim of selecting the best teacher-candidates for the teacher-training programmes.

In Malaysia, the teacher-candidates are selected by the Ministry of Higher Education for local university entries, whereas the Ministry of Education is in charge of the teaching institute entries. Candidates applying for the teacher training programme are increasing each year. This is obvious when there were about 56000 applicants who applied for the teacher training program in local universities in 2008. However, only 9900 applicants qualified to enter the training programmes in local universities. Basically, there are three components in the selection procedures. Initially, teacher training or education programme applicants are filtered based on their academic achievements. In the second stage, the selected candidates sit for Malaysian Educators Selection Inventory (MedSi) examination which contains 300 items regarding personality, interest towards 
career, integrity and emotional qualities. This exam is constructed by the MedSI instrument development committee, consisting of experts from several public higher education institutions arranged by the authority concerned and the last stage is the interview session (Universiti Pendidikan Sultan Idris, 2008). In the interview session, the interviewers will evaluate the applicants. The good performers in the interview will be short-listed to pursue the teacher training programmes.

As previously mentioned, since two ministries are responsible for all teacher training or educational programmes, the requirement and criteria are established differently by these two ministries. Furthermore, based on discussions with the experts who have experience in interviewing the candidates, who were also the respondents of this study, it is learned that part of the decision-making in the selection-process is still highly dependent on subjective human judgement especially during the interviews. This may lead to certain inconsistencies. Hence, a study to explore the selection criteria used in the current selection process is deemed necessary. It is hoped that this study will be able to answer the questions being posed regarding the selection criteria and those selected can later be used as a basis for the development of the selection model of teacher candidates.

\section{Selection Criteria}

In Malaysia, there exists different sets of criteria used by different authorities. For example, in the Malaysia Educators Selection Inventory (MedSI) exam, the applicants are evaluated on intrinsic qualities such as personality, interest towards the teaching career, integrity and emotional. The selection criteria used during the interview session by the Ministry of Education is different from the one used by the Ministry of Higher Education. In addition, the prioritization given to the criteria is also different among these authorities.

Many researches (Goldhaber, 2002; Walker, 2008; Harslett, Harrison, Godfrey, Partington \& Richer, 1998; Thompson, Greer, \& Geer, 2007; Wang, Gibson \& Slate, 2007; Donaldson, Vincent, \& McIntire, 1987; Hammond \& Youngs, 2002) had been done to study the evaluationcriteria in teacher selection. Different concerns have been given to the criteria with various arguments. The methods used in these studies are interviews with various groups such as teachers and students, and questionnaires in the Likert Scale format. Furthermore, the 
results of these studies were discussed by using simple descriptive analyses which implies that no specific quantitative multi-criteria based methods were used in the studies.

But this study has used both types of data, primary and secondary, in identifying the criteria. The source of the primary data is the experts who have experience in interviewing the candidates. These experts were asked to comment and justify the criteria obtained from the secondary source, the literature. Besides that, they were asked to prioritize the criteria by comparing the criteria in terms of their importance in a pair-wise manner. Their judgments were analysed by a powerful multi-criteria method, Analytic Hierarchy Process (AHP) (Ho, 2007; Saaty, 1980).

The Analytic Hierarchy Process (AHP) is a mathematical technique developed by Saaty in the 1970s for multi-criteria decision-making (Saaty, 1980; 1990; 1994). It enables people to make decisions involving many kinds of concerns including applications in group decisionmaking (Syamsuddin \& Hwang, 2009), business (Kumar Parashar \& Haleem, 2009), industry (Burdurlu \& Ejder, 2003), healthcare (Liberatore \& Nydick, 2008), management (Liu, Berger, Zeng \& Gerstenfeld, 2008; Rafikul Islam, 2007), manufacturing (Bhutta \& Huq, 2002), solid-waste treatment (Mohd Armi, Latifah, Wan Nor Azmin Sulaiman \& Rafikul Islam, 2007) and higher institutions' strategic planning (Liberatore \& Nydick, 1997). Generally, AHP is conducted in three steps in making judgments about the priority of the criteria (Taylor III, 2010).

In step 1, the respondents or evaluators are asked to perform pairwise comparisons among the criteria. The scale is from 1 to 9 , and the meaning of the rating is given in Table 1 (Saaty, 1980).

Table 1

Preference Scale of AHP Technique

\begin{tabular}{lc}
\hline Verbal judgment & Numerical rating \\
\hline Extremely more important & 9 \\
Very strongly more important & 7 \\
Strongly more important & 5 \\
Moderately more important & 3 \\
Equally important & 1 \\
For compromises between the above values & $2,4,6,8$ \\
\hline
\end{tabular}


If there is $m$ criteria to be evaluated, then the respondent has to make $m(m-2) / 2$ comparisons. For example, if the number of criteria is 5 , then there should be 10 pairs of criteria to be compared. Suppose criterion 1 is compared with criterion 2 . If criterion 1 is 'very strongly more important' than criterion 2, then $m_{12}=7$, and $m_{21}=1 / 7$. All the pairwise comparisons collected from each respondent were transferred into matrix form, $M$, where $m_{j k}=1 / m_{k j^{\prime}} k>j$ such as in Figure 1.

$M=\left[\begin{array}{cccc}1 & m_{12} & \ldots & m_{1 n} \\ m_{21} & 1 & \ldots & m_{2 n} \\ \vdots & \vdots & \vdots & \vdots \\ m_{n 1} & m_{n 2} & \ldots & 1\end{array}\right]$
Figure 1. Matrix $M$.

Obviously, as the number of criteria increases, the number of pairwise comparisons also increases, which is one of the major drawbacks of AHP. Besides that, before computing the weights based on pairwise judgments in Step 3, the degree of consistency is measured by the Consistency Index $(C I)$ in Step 2. Perfect consistency implies a value of zero. However, perfect consistency cannot be demanded since human beings are often biased and inconsistent in subjective judgments. Therefore, it is considered acceptable for some inconsistency up to a certain degree. The $C I$ for $M$ is calculated as

$$
C I=\frac{\lambda_{\max }-n}{n-1}
$$

where ${ }^{\lambda} \max$ is the maximum eigen vector of matrix $M$. If the consistency ratio, $C I / R I<0.10$, then the degree of consistency is satisfactory, where the random index, $R I$ values are given in Table 2 (Taylor III, 2004). Some researchers even avoided doing pair-wise comparison altogether. For example, some applied simpler approaches such as the simple scoring model (Stevenson \& Ozgur, 2007), rank-based methods (Roberts \& Goodwin, 2003), and the ELECTRE III technique (Li \& Wang, 2007). However, these techniques also received comments due to lack of good attributes that appear in AHP, particularly with respect to the pair-wise comparison. 
IJMS 20 (2), (15-28) (2013)

Table 2

Random Index, RI, Values

\begin{tabular}{cc}
\hline Number of criteria, $(n)$ & Random index $(\mathrm{RI})$ \\
\hline 2 & 0.00 \\
3 & 0.58 \\
4 & 0.90 \\
5 & 1.12 \\
6 & 1.24 \\
7 & 1.32 \\
8 & 1.41 \\
\hline
\end{tabular}

In the third step, the weight for criterion $j, j=1,2, \ldots, n$, for each respondent's evaluation is calculated by using the following formula:

$$
w_{j}=\frac{1}{n} \sum_{k=1}^{n} \frac{m_{j k}}{\sum_{i=1}^{n} m_{i k}}
$$

This process is repeated for every criterion considered. This study involves more than one respondent; so in order to obtain the final single value of the weight of each criteria, the geometric mean is used to aggregate the individual judgments. From the weight values, the ranking of the criteria can be determined with the consideration that the criterion which is more important that the other criteria must have higher weight and higher ranking. (Forman \& Peniwati, 1998; Ramanathan \& Ganesh, 1994; Van Den Honert \& Lootsma, 1996). If $p$ respondents were involved in the evaluation, the final weight for criteria $j$ is obtained as a geometric mean, that is, by taking the $p$ th root of the product of all $p$ weights of that criterion, as follows:

$$
w_{j}=\sqrt[p]{w_{j(1)} \times \ldots \times w_{j(p)}}
$$

\section{Results and Discussion}

\section{The Respondents}

Twelve respondents were involved in the study. All of them have formal training as teachers. About 40 per cent of them are with doctorate of philosophy $(\mathrm{PhD})$ degrees, and the others are with master's degrees. 
All of them have experience in conducting interviews. More than 40 per cent of them have been interviewers for more than six years.

\section{The Criteria}

In terms of the criteria, three main criteria were identified, namely content of knowledge (CK), communication skill (CS) and personality (P). Table 3 shows the summary of the sub-criteria.

Table 3

Teacher Selection Criteria

\begin{tabular}{|c|c|c|}
\hline Content of knowledge & Communication skills & Personality \\
\hline General K & Pronunciation & Attire \\
\hline Subject matter K & Clarity & $\begin{array}{l}\text { Behaviours \& } \\
\text { ethics poise }\end{array}$ \\
\hline Current issue & Construction ideas & Leadership \\
\hline \multirow[t]{4}{*}{$\begin{array}{l}\text { Real or authentic } \\
\text { situation }\end{array}$} & $\begin{array}{l}\text { Language } \\
\text { proficiency }\end{array}$ & Motivation \\
\hline & Fluency & Confidence \\
\hline & $\begin{array}{l}\text { Completeness of } \\
\text { statement }\end{array}$ & Sensitivity \\
\hline & & Creativity \\
\hline
\end{tabular}

The criteria identified are justified based on literature review and experts' ophinions so as to have a consensus of these criteria. Content of knowledge (CK) is one of the important criteria contributing to teachers' effectiveness (Hammonds \& Youngs, 2002). A teacher with good content of knowledge may contribute to students' achievement. $\mathrm{CK}$ has a wide scope. It was decomposed into four sub-criteria: general knowledge, subject matter knowledge, current issues and real authentic situations.

"General knowledge" and "current issues" are almost similar but they have subtle differences. "Current issues" is awareness of issues currently taking place whereas "general knowledge" is awareness of historical issues and also current issues as perceived by respondents. Subject matter knowledge is another sub-criterion of content of knowledge. Subject matter knowledge is knowledge about subjects assigned to them. For instance, if an applicant applies for an English education course, then it is compulsory for the applicant 
to be proficient in that particular subject. On the other hand, a real or authentic situation is another sub-criterion where the candidates are given various situations and the applicants are tested on their spontaneous decisions or actions. This criterion may evaluate the candidates' spontaneous and logical decisions.

Communication skill (CS) is another criterion perceived to be important in selecting teacher candidates. It is also known as verbal ability. This criterion is essential because good communication skills help the teachers to communicate effectively and enhance students' understanding (Donaldson et al., 1987; Wang et al., 2007). Pronunciation, clarity, constructive ideas, language proficiency, fluency and completeness of statements are listed as sub-criteria of communication skills. Good pronunciation and clarity are essential to explain subject matter, opinions as well as ideas well and clearly. Constructive ideas enable teachers to comment on the subject matter and also to answer the questions posed by students. Therefore, these criteria are suggested as evaluation criteria in interview sessions. Another proposed sub-criterion, language proficiency, is to evaluate the ability of applicants in terms of how proficient they are in a particular language. This is because language course applicants should be proficient in a particular language as mentioned by the respondents. They also evaluate the teacher candidate applicants in terms of fluency and completeness of statement, where the candidates are expected to speak fluently and communicate well. In addition, each statement in the conversation of the applicants should be in correct order and complete.

Besides CK and CS, personality $(\mathrm{P})$ is also identified as an evaluation criterion of teacher candidates. It is divided into eight sub-criteria to give a comprehensive evaluation on one's personality. Teacher candidates are to be evaluated in terms of attire or appearance. This is because, teachers should be attractive in appearance and well dressed in order to create good images among the students as stated by Beckert (1965). At the same time, poise is another important evaluation criterion identified in this research. It may be justified as positive attitudes or thinking, involving, being friendly and caring (Thompson et al., 2007). In addition, teachers should have motivation for entering into the teaching field (Brookhart \& Freeman, 1992). The applicants need to be evaluated for motivation because they need to be highly motivated to remain in the challenging teaching career. In addition, a teacher should establish and maintain a professional leadership role so as to be a good role model to the students. Another 
sub-criterion of personality is confidence. Brookhart and Freeman (1992) defined confidence as self-assurance, optimism, anxiety and concerns. This criterion is to examine candidates' capability to deliver their opinions without any hesitation. The respondents suggested that confidence of applicants may be measured by eye contact and confident voices during interview sessions. The sub-criterion, tolerance, is to evaluate candidates in terms of patience and being easy going. Sensitive teachers are always aware of their students' needs and wants. Walker (2008) also mentioned that teachers should be environmentally conscious. For instance, if a student is not well, the teacher should be aware about the situation and take essential actions to help the student. Lastly, the respondents also suggested creativity as an evaluation or selection criterion in interview sessions. Teachers should be creative in delivering lessons and using different approaches for teaching purposes.

\section{Weights and Ranking of the Main Criteria}

As discussed previously, after the criteria had been identified, each respondent was asked to compare the importance of each criterion to another criterion, and the evaluation was transformed in a matrix as in Figure 1. Then the weights of the criteria would be calculated by using equation (1). For the main criteria, the weights obtained and the consistency index for each evaluation is illustrated in Table 4. Based on the Table, almost all respondents gave highest weight to $\mathrm{C}_{2}$, which represents CS. This shows that CS is the most important as compared to $\mathrm{CK}$ and P. Meanwhile, the consistency ratio, as in the last column of the table, which was calculated by equation (2) for all evaluations is below 0.1 . This means that all evaluations met the consistencysatisfactory requirement.

Table 4

Weights and Consistency Ratio for Main Criteria

\begin{tabular}{ccccc}
\hline Respondent & $\mathrm{C}_{1}$ & $\mathrm{C}_{2}$ & $\mathrm{C}_{3}$ & $\mathrm{CI} / \mathrm{RI}$ \\
\hline 1 & 0.106 & 0.633 & 0.261 & 0.033 \\
2 & 0.057 & 0.649 & 0.295 & 0.07 \\
3 & 0.074 & 0.643 & 0.283 & 0.057 \\
4 & 0.074 & 0.643 & 0.283 & 0.057 \\
\hline & & & & (continued)
\end{tabular}


IJMS 20 (2), (15-28) (2013)

\begin{tabular}{ccccc}
\hline Respondent & $\mathrm{C}_{1}$ & $\mathrm{C}_{2}$ & $\mathrm{C}_{3}$ & $\mathrm{CI} / \mathrm{RI}$ \\
\hline 5 & 0.283 & 0.643 & 0.074 & 0.057 \\
6 & 0.261 & 0.633 & 0.106 & 0.033 \\
7 & 0.106 & 0.633 & 0.261 & 0.033 \\
8 & 0.106 & 0.633 & 0.261 & 0.033 \\
9 & 0.106 & 0.633 & 0.261 & 0.033 \\
10 & 0.106 & 0.633 & 0.261 & 0.033 \\
11 & 0.261 & 0.633 & 0.106 & 0.033 \\
12 & 0.126 & 0.416 & 0.458 & 0.008 \\
\hline
\end{tabular}

These individual judgments were aggregated by using the geometric mean approach as in equation (3). For example, the value 0.121 was obtained as a geometric mean of all values in column 2 of Table 4 , that is by taking the twelfth root of the product of all values in column 2 of Table 4. Table 5 summarized the final weights and rankings of the three main criteria.

Table 5

Weights and Ranking of Main Criteria

\begin{tabular}{lcc}
\hline \multicolumn{1}{c}{ Criteria } & Weights & Rank \\
\hline Content of knowledge & 0.121 & 3 \\
Communication skills & 0.615 & 1 \\
Personality & 0.217 & 2 \\
\hline
\end{tabular}

Based on Table 5, CS was chosen by the respondents to be the most important criterion with a very high weight value, that is 0.615 , and followed by CK and P.

\section{Weights and Ranks of the Sub-criteria}

Tables 6, 7 and 8 show the normalized weights of the sub-criteria and represent the final weights and rankings of the sub-criteria of CK, CS and P respectively. For the sub-criteria CK, 'subject matter knowledge' was agreed by the respondents to be the most important one, followed by real or authentic situation', 'current issues', and 'general knowledge' as summarized in Table 6. 
Table 6

Weights and Rank for Content of Knowledge Sub-criteria

\begin{tabular}{lcc}
\hline Criteria & Weights & Rank \\
\hline General knowledge & 0.063 & 4 \\
Subject matter knowledge & 0.530 & 1 \\
Current issues & 0.121 & 3 \\
Real or authentic situations & 0.286 & 2 \\
\hline
\end{tabular}

Table 7 shows the weights and rankings for sub-criteria CS, where 'constructive idea' was selected as the most important sub-criteria, while pronunciation was ranked at the last position. For the subcriteria P, as illustrated in Table 8, 'confidence', and 'tolerance' were in the first and second important positions respectively, while 'attire' or 'appearance' was the least important.

Table 7

Weights and Rank for Communication Skills Sub-criteria

\begin{tabular}{lcc}
\hline \multicolumn{1}{c}{ Criteria } & Weights & Rank \\
\hline Pronunciations & 0.031 & 6 \\
Clarity & 0.053 & 5 \\
Constructive ideas & 0.442 & 1 \\
Language proficiency & 0.246 & 2 \\
Fluency & 0.127 & 3 \\
Completeness of statement & 0.100 & 4 \\
\hline
\end{tabular}

Table 8

Weights and Ranks for Personality Sub-criteria

\begin{tabular}{lcc}
\hline \multicolumn{1}{c}{ Criteria } & Weights & Rank \\
\hline Attire/Appearance & 0.006 & 8 \\
Behaviour \& ethics or poise & 0.009 & 7 \\
Leadership & 0.022 & 5 \\
Motivation & 0.042 & 3 \\
Confidence & 0.084 & 1 \\
Tolerance & 0.063 & 2 \\
Sensitivity & 0.017 & 6 \\
Creativity & 0.034 & 4 \\
\hline
\end{tabular}




\section{Conclusion}

This study has successfully identified three main criteria and the corresponding sub-criteria in selecting teacher candidates to enter the training programmes. These criteria are reliable, valid and can be used during the interview session since the criteria were determined after a thorough literature and experts' review. These criteria and the rankings are also very much significant to those who are interested to become teachers in the future.

These criteria weights can later be combined with the achievement of teacher candidates with respect to each criterion and sub-criterion and can become the basis for constructing a teacher-selection model. To make the model more usable, it can be upgraded as a decisionsupport system and can be used by the interviewers who will conduct the related interview. Apparently the proposed model may assist in selecting the most suitable candidates in terms of communication skills, content of knowledge and personality.

The major limitation of this study was the respondents, who consisted of interviewers of teacher candidates from one local university only. Thus, the generalization of the multi-criteria selection may be an issue. In order to generalize the findings, the perceptions of all of the interviewers of teacher candidates are essential.

\section{Acknowledgements}

This research is funded by Center for Testing, Measurement and Appraisal (CeTMA), Universiti Utara Malaysia Research Grant Scheme.

\section{References}

Bhutta, K. S., \& Huq, F. (2002). Supplier selection problem: A comparison of the total cost of ownership and analytic hierarchy process approaches. Supply Chain Management an International Journal, 7(3), 126-135.

Beckert, R. F. (1965). Teacher development. The Accounting Review, $40(2), 434-440$.

Brookhart, S. M., \& Freeman, D. J. (1992). Characteristics of entering teacher candidates. Review of Educational Research, 62(1), 37-60. 
Burdurlu, E., \& Ejder, E. (2003). Location choice for furniture industry firms by using analytic hierarchy process G.U. Journal of Science, 16(20), 369-373.

Donaldson, G. A., Vincent, P., \& McIntire, W. (1987). Teacher selection of master teacher criteria: Giving the professional local control. Annual Meeting of the American Educational Research Association (pp. 1-23).

Forman, E., \& Peniwati, K. (1998). Aggregating individual judgments and priorities with the analytical hierarchy process. European Journal of Operational Research, 108, 165-169.

Goldhaber, D. (2002). The mystery of good teaching. Journal of Opinion and Research, 1(2), 50-55.

Hammond, L. D., \& Youngs, P. (2002). Defining "Highly qualified teachers": What does "Scientifically-based research" Actually tell us? Research news and comment. Retrieved from http://aera.net

Harslett, M., Harrison, B., Godfrey, J., Partington, G., \& Richer, K. (1998). Teacher perceptions of the characteristics of effective teachers of aboriginal middle school students. Retrieved from http://ajte. education.ecu.edu.au

Ho, W. (2007). Integrated analytical hierarchy process and its applications - A literature review. Journal of Operational Research, 186, 211-228.

Kumar, S., Parashar, N., \& Haleem, A. (2009). Analytic hierarchy process applied to vendor selection problem: Small scale, medium scale, and scale industries. Business Intelligence Journal, l2(2), 355-362.

Li, H. F., \& Wang, J. J. (2007). An improved ranking methods for ELECTRE III. Retrieved from http://ieeexplore.ieee.org

Liberatore, M. J., \& Nydick, R. L. (1997). Group decision making in higher education using the analytic hierarchy process. Research in Higher Education, 38(5), 593-614.

Liberatore, M. J., \& Nydick, R. L. (2008). The analytic hierarchy process in medical and healthcare decision making. European Journal of Operational Research, 46(2), 158-166.

Liu, L. B., Berger, P., Zeng, A., \& Gerstenfeld, A. (2008). Applying the analytic hierarchy process to the offshore outsourcing location decision. Supply Chain Management, 13(6), 435-440.

Ministry of Higher Education. (2010). Retrieved from http://www. moe.gov.my

Mohd Armi., Latifah., Wan Nor Azmin Sulaiman, \& Rafikul Islam. (2007). Application of the Analytical Hierarchy Process (AHP) for selecting an appropriate solid waste treatment technology. In 2nd National Intelligent Systems and Information Technology Symposium (ISITS'07), Oct 30-31, Serdang, Malaysia. 
Rafikul Islam. (2007). MBNQA criteria in education: Assigning weights from a Malaysian perspective and proposition for an alternative evaluation scheme. International Transactions in Operational Research, 14, 373-394.

Ramanathan, R., \& Ganesh, L. S. (1994). Group preference aggregation methods employed in AHP: An evaluation and an intrinsic process for deriving members' weightages. European Journal of Operational Research, 79, 249-265.

Roberts, R., \& Goodwin, P. (2003). weight approximations in multiattribute decision models. Journal of Multi-Criteria Decision Analysis, 11, 291-303.

Saaty, T. L. (1980). The analytic hierarchy process. New York: McGraw-Hill.

Saaty, T. L. (1990). Multi criteria decision making: The analytic hierarchy process. Pittsburgh: RWS Publication.

Saaty, T. L. (1990). Multi criteria decision making: The analytic hierarchy process for decision in a complex world (3rd ed.). Pittsburgh: RWS Publication.

Sang, M. S. (2005). Ilmu pendidikan untuk KPLI. Subang Jaya: Kumpulan Budiman.

Stevenson, W. J., \& Ozgur, C. (2007). Introduction to management science with spreadsheets. Boston: McGraw Hill.

Syamsudin, I., \& Hwang, T. (2009). The application of AHP to evaluate information security policy decision making. International Journal of Simulation Systems, Science \& Technology, 10(5), 33-37.

Taylor III, B. W. (2004). Introduction to management science (8th ed.). New Jersey: Pearson Prentice Hall.

Taylor III, B. W. (2010). Introduction to management science (10th ed.). Boston: Pearson Prentice Hall.

Thompson, S., Greer, J. G., \& Geer, B. B. (2007). Highly qualified for successful teaching: Characteristics every teacher should possess. Retrieved from http://www.usca.edu

United Sates of America Deparment of Education. (2008). Retrieved from www.edu.gov

Universiti Pendidikan Sultan Idris. (2008). MEDSI Test. Retrieved from http://akademik.upsi.edu.my

Van Den Hornert, R. C., \& Lootsma, F. A. (1996). Group preference aggregation in the multiplicative AHP: The model of the group decision process and Pareto optimality. European Journal of Operational Research, 96, 363-370.

Walker, R. J. (2008). Twelve characteristics of an effective teacher. Retrieved from http://www.pilambda.org

Wang, J., Gibson, A. M., \& Slate, J. R. (2007). Effective teachers as viewed by students at a 2 year college: A multistage mixed analysis. Issues in Educational Research, 17(2), 272-295. 